(Journal of Civil Engineering, Building and Transportation)

Available online http://ojs.uma.ac.id/index.php/jcebt

\title{
Pemanfaatan Limbah Serbuk Gergaji Kayu Sebagai Subtitusi Campuran Bata Ringan Kedap Suara
}

\section{Utilization of Wood Sawdust Waste As a Mixed Substitution of Soft Mixed Brick}

\author{
R. Exaudi Simon Purba*, Irwan \& Nurmaidah \\ Program Studi Teknik Sipil, Fakultas Teknik, Universitas Medan Area, Indonesia \\ *Coresponding Email: E-mail : rajaexaudi@yahoo.co.id
}

\begin{abstract}
Abstrak
Serbuk kayu adalah limbah yang diperoleh dari hasil penggergajian kayu yang menggunakan mesin maupun manual. Serbuk gergaji kayu dapat juga digunakan sebagai peredam suara. Pada penelitian ini, limbah kayu dimanfaatkan untuk pengganti sebagian agregat halus yang digunakan pada campuran pembuatan bata ringan. Pada penelitian ini bertujuan membahas tentang karakteristik kedap suara dengan pemanfaatan limbah serbuk gergaji kayu, semen PC, dan pasir sebagai bahan pembentuknya. Pada kajian ini serbuk gergaji kayu yang digunakan adalah berasal dari Sumatera Utara dengan variasi komposisi $0 \%, 20 \%$, dan 30\% (massa), sedangkan komposisi material lainnya dibuat tetap. dengan ukuran serbuk kayu yang dipakai $0,25 \mathrm{~mm}-2,0 \mathrm{~mm}$. Untuk pengujian beton peredam suara akan dibuat benda uji berbentuk silinder dengan diameter $11 \mathrm{~cm}$ dan tebal $6 \mathrm{~cm}$ sebanyak 6 benda uji. Hasil dari penelitian ini menunjukkan pada campuran 30\% serbuk gergaji kayu yaitu pada variasi ke-III menunjukkan nilai koefisien serap bunyi terbesar yaitu 0.6832 dengan frekuensi $1000 \mathrm{~Hz}$ dengan koefisien absorbsi 0,50\% dan dengan kecepatan rambat gelombang bunyi menunjukkan 683,2 $\mathrm{m} / \mathrm{det}$. Dari penelitian ini dapat disimpulkan bahwa semakin besarnya persentase campuran serbuk gergaji kayu maka kemampuan untuk meredam suara semakin besar.
\end{abstract}

Kata Kunci : Absorbsi, Akustik, Bata Ringan Kedap Suara, Serbuk Gergaji Kayu

\begin{abstract}
Wood powder is a waste obtained from sawmills using both machinery and manuals. Sawdust can also be used as a silencer. In this study, wood waste is used for partial substitution of fine aggregate used in light brick making mix. In this study discusses the characteristics of soundproofing with the utilization of wood sawdust waste, PC cement, and sand as its forming material. In this study, wood sawdust used is from North Sumatra with variation of 0\%, 20\%, and 30\% (mass) compositions, while other material compositions are made constant. With a wooden powder size of $0.25 \mathrm{~mm}-2.0 \mathrm{~mm}$. For testing of silencer will be made of cylindrical test object with diameter $11 \mathrm{~cm}$ and thickness $6 \mathrm{~cm}$ as much as 6 specimen. The results of this study indicate that the $30 \%$ sawdust mixture in the third variation shows the highest absorption coefficient value of 0.6832 with the frequency of $1000 \mathrm{~Hz}$ with absorption coefficient $0.50 \%$ and with the velocity of the sound wave indicates $683.2 \mathrm{~m} / \mathrm{s}$. From this research, it can be concluded that the greater the percentage of sawdust mixture, the greater the ability to muffle the noise.

Keywords: Absorption, Acoustic, , Lightweight soundproof brick, Sawdust.
\end{abstract}

How to Cite: Purba E.R.S, Lubis, K, \& Nurmaidah. (2017), Pemanfaatan Limbah Serbuk Gergaji Kayu Sebagai Subtitusi Campuran Bata Ringan Kedap Suara, JCEBT (Journal of Civil Engineering, Building and Transportation). 1 (2): 87-95. 
R. Exaudi Simon Purba, Irwan \& Nurmaidah, Pemanfaatan Limbah Serbuk Gergaji Kayu Sebagai Subtitusi

\section{PENDAHULUAN}

Makin meningkatnya kebutuhan perumahan saat ini menyebabkan kebutuhan akan bahan bangunan semakin meningkat pula. Seperti kita ketahui bersama, bahan yang digunakan untuk bangunan terdiri dari bahan-bahan atap, dinding dan lantai. Salah satu masalah dilapangan saat ini yang perlu segera diatasi adalah masalah kebutuhan batu bata sebagai bahan dinding perumahan dan efek kerusakan lingkungan yang ditimbulkan. Sebagaimana diketahui, kebutuhan masyarakat akan perumahan tidak pernah surut bahkan selalu meningkat dari tahun ke tahun. Adapun salah satu permasalahan utama dalam menyediakan rumah di Indonesia adalah tingginya biaya konstruksi bangunan dan lahan. Selama ini berbagai penelitian sudah dilakukan tetapi masih belum ditemukan alternatif teknik konstruksi yang effisien serta penyediaan bahan bangunan dalam jumlah besar dan ekonomis. Ketika kita menyadari bahwa bangunan di sepanjang tepi jalan sangat potensial menderita kebisingan, penting kiranya dipikirkan cara-cara penanggulangannya.(Mediastika, 2005). Hal tersebut dapat memberikan suatu alternatif untuk memanfaatkan limbahlimbah industri yang dibiarkan begitu saja. Serbuk kayu (sawdust) adalah limbah yang diperoleh dari hasil penggergajian kayu yang menggunakan mesin maupun manual. Serbuk gergaji kayu dapat juga digunakan sebagai peredam suara. Kualitas dari bahan peredam suara ditunjukkan dengan harga $\alpha$ (koefisien penyerapan bahan terhadap bunyi), semakin besar $\alpha$ maka semakin baik digunakan sebagai peredam suara. Nilai berkisar dari 0 sampai 1 . Jika $\alpha$ bernilai 0 , artinya tidak ada bunyi yang diserap. Sedangkan jika $\alpha$ bernilai 1, artinya 100\% bunyi yang datang diserap oleh bahan. Pada penelitian ini, limbah kayu dimanfaatkan untuk pengganti sebagian agregat halus yang digunakan pada campuran pembuatan bata ringan. Kayu telah digunakan sebagai bahan struktur sejak dahulu.Kayu mempunyai kekuatan tarik dan tekan, dan secara stuktural cocok untuk berperan sebagai elemen yang memikul beban jenis tekan aksial, tarik aksial, dan beban lentur. (Angus J.Macdonald, 2001). Demikian halnya dengan serbuk kayu pengergajian merupakan salah satu jenis kayu partikel yang berukuran 0,25 mm - 2,00 mm, bobotnya ringan dalam keadaan kering dan mudah diterbangkan oleh angin. Kandungan kimia kayu adalah selulosa, lignin dan zat lain (termasuk zat gula). Dinding sel tersusun sebagian besar oleh selulosa (C6H1005). Selulosa adalah suatu 
bahan yang tidak begitu asing lagi bagi manusia meskipun merupakan karbohidrat selulosa bukanlah sumber makanan bagi manusia. Lignin adalah suatu campuran zat - zat organik yang terdiri dari zat karbon, zat air atau hidrogen dan oksigen. Serbuk gergaji kayu mengandung komponen utama yaitu selulosa, hemiselulosa, lignin dan zat ekstraktif kayu. Limbah mempunyai pengertian sebagai bahan hasil sampingan, hasil ikatan dan hasil sisa yang sudah serta belum dimanfaatkan untuk produksi tertentu setelah melewati proses lanjutan ataupun tidak. Pendaurulangan limbah gergajian kayu dipandang perlu jika memang memiliki manfaat lebih dan bisa dipertanggungjawabkan secara teknis dan terlebih jika mampu menjadikan bahan yang murah serta mudah diaplikasikan. Kebutuhan material atau bahan untuk dinding peredam suara hingga saat ini masih cenderung sulit didapatkan, dan kalaupun ada biasanya dengan harga cukup mahal. Sedangkan kebutuhan akan bahan peredam suara semakin banyak dibutuhkan bukan hanya di studio, tempat konser musik, ruang meeting dll, tetapi sampai ditingkat rumah tangga pun diperlukan karena kebisingan bisa mengganggu seseorang dalam beraktivitas. Strategi penanganan kebisingan ruang dalam dapat dengan mengurangi kebisingan dengan bahan peredam (seperti yang ditulis Prasasto Satwiko, dalam buku Fisika Bangunan).

Dengan melihat latar belakang di atas, maka dalam penelitian ini akan mengembangkan penelitian mengenai penambahan serbuk kayu sebagai bahan tambah beton ringan yang digunakan sebagai konstruksi dinding kedap suara. Oleh karena itu penulis mengambil judul "Pemanfaatan limbah serbuk gergaji kayu sebagai subtitusi campuran bata ringan kedap suara".

\section{METODE PENELITIAN}

Metode penelitian yang digunakan adalah eksperimental pengujian kebisingan suara (sound absortion coefficient) dilakukan di laboratorium Noise \& Vibration Control, Teknik Mesin Universitas Sumatera Utara (USU). Pada penelitian ini membahas tentang karakteristik kedap suara dengan pemanfaatan limbah serbuk gergaji kayu, semen PC, dan pasir sebagai bahan pembentuknya. Pada kajian ini serbuk gergaji kayu yang digunakan adalah berasal dari Sumatera Utara dengan variasi komposisi $0 \%, 20 \%$, dan 30\% (massa), sedangkan komposisi material lainnya dibuat tetap. Penelitian ini dilakukan berdasarkan penelitian sebelumya oleh Muslimin Lubis dengan 
R. Exaudi Simon Purba, Irwan \& Nurmaidah, Pemanfaatan Limbah Serbuk Gergaji Kayu Sebagai Subtitusi

variasi $0 \%, 1 \%, 2 \%, 3 \%, 4 \%, 5 \%$ dimana hasil optimum kedap suara diperoleh dengan komposisi persentase serbuk sebesar 5\%, dengan ukuran serbuk kayu yang dipakai 0,25 mm - 2,0 mm. Untuk pengujian beton peredam suara akan dibuat benda uji berbentuk silinder dengan diameter $11 \mathrm{~cm}$ dan tebal $6 \mathrm{~cm}$ sebanyak 6 benda uji.

\section{Komposisi campuran beton yang}

\section{digunakan}

a. Variasi I $0 \%$ (semen $20 \%$ : pasir $80 \%$ : serbuk gergaji kayu 0\%) dengan faktor air semen 0,35 yaitu untuk berat semen yang dibutuhkan untuk 1 wadah dimana $20 \%$ dari volume wadah $=20 \% \times 569,91 \mathrm{~cm}^{3}=113,982 \mathrm{~cm}^{3}$ Jadi, berat yang dibutuhkan $=113,982 \mathrm{~cm}^{3} \mathrm{x}$ berat jenis semen $=113,982 \mathrm{~cm}^{3} \times 3,1 \mathrm{gr} / \mathrm{cm}^{3}$ $=353,34 \mathrm{gr}$

Untuk pasir yang dibutuhkan untuk 1 wadah dimana $80 \%$ dari volume wadah

$=80 \% \times 569,91 \mathrm{~cm}^{3}$

$=455,92 \mathrm{~cm}^{3}$

Jadi, berat yang dibutuhkan

$=455,92 \mathrm{~cm} 3 \times$ Berat jenis pasir

$=455,92 \mathrm{~cm} 3 \times 1,4 \mathrm{gr} / \mathrm{cm} 3$

$=638.28 \mathrm{gr}$

Untuk berat serbuk gergaji kayu yang dibutuhkan untuk 1 wadah dimana $0 \%$ dari volume wadah

$$
=0 \% \times 569,91 \mathrm{~cm}=0
$$

Untuk faktor air semen yang dibutuhkan adalah $35 \%$, dimana 35\% dari volume wadah

$$
\begin{aligned}
& =35 \% \times 569,91 \mathrm{~cm}^{3} \\
& =199,46 \mathrm{~cm}^{3}
\end{aligned}
$$

Jadi berat yang dibutuhkan

$=199,46 \mathrm{~cm}^{3} \mathrm{x}$ berat jenis air

$=199,46 \mathrm{~cm}^{3} \times 1 \mathrm{gr} / \mathrm{cm}^{3}$

$=199,46 \mathrm{gr}$

Jadi jumlah total berat campuran untuk variasi $0 \%$ (semen + pasir + Serbuk gergaji kayu)

$=353,34 \mathrm{gr}+638.28 \mathrm{gr}+0 \mathrm{gr}+$ $199,46 \mathrm{gr}$

$$
=1191,08 \mathrm{gr}
$$

b. Variasi II 20\% (Semen 20\% :Pasir 60\%: Serbuk Gergaji Kayu 20\%) dengan faktor air semen 0,35 yaitu:

Untuk berat semen yang dibutuhkan untuk 1 wadah dimana $20 \%$ dari volume wadah

$=20 \% \times 569,91 \mathrm{~cm}^{3}$

$=113,982 \mathrm{~cm}^{3}$

Jadi berat yang dibutuhkan

$=113,982 \mathrm{~cm}^{3} \mathrm{x}$ berat jenis semen

$=113,982 \mathrm{~cm}^{3} \times 3,1 \mathrm{gr} / \mathrm{cm}^{3}$

$=353,34 \mathrm{gr}$

Untuk pasir yang dibutuhkan untuk 1 wadah dimana $60 \%$ dari volume wadah

$=60 \% \times 569,91 \mathrm{~cm}^{3}$

$=341,94 \mathrm{~cm}^{3}$

Jadi berat yang dibutuhkan

$=341,94 \mathrm{~cm}^{3} \times$ Berat jenis pasir 


$$
\begin{aligned}
& =341,94 \mathrm{~cm}^{3} \times 1,4 \mathrm{gr} / \mathrm{cm}^{3} \\
& =478,71 \mathrm{gr}
\end{aligned}
$$

Untuk berat serbuk gergaji kayu yang dibutuhkan untuk 1 wadah dimana 20\% dari volume wadah

$$
=20 \% \times 569,91 \mathrm{~cm}^{3}=113,982 \mathrm{~cm}^{3}
$$

Jadi berat yang dibutuhkan

$=113,982 \mathrm{~cm}^{3} \mathrm{x}$ berat jenis serbuk kayu

$$
\begin{aligned}
& =113,982 \mathrm{~cm}^{3} \times 0,28 \mathrm{gr} / \mathrm{cm}^{3} \\
& =31,9 \mathrm{gr}
\end{aligned}
$$

Untuk faktor air semen yang dibutuhkan adalah $35 \%$ dimana 35\% dari volume wadah

$$
\begin{aligned}
& =35 \% \times 569,91 \mathrm{~cm}^{3} \\
& =199,46 \mathrm{~cm}^{3}
\end{aligned}
$$

Jadi berat yang dibutuhkan

$=199,46 \mathrm{~cm}^{3} \mathrm{x}$ berat jenis air

$=199,46 \mathrm{~cm}^{3} \times 1 \mathrm{gr} / \mathrm{cm}^{3}$

$=199,46 \mathrm{gr}$

Jadi jumlah total berat campuran untuk variasi 20\% (semen + pasir +Serbuk gergaji kayu)

$=353,34 \mathrm{gr}+478,71 \mathrm{gr}+31,9 \mathrm{gr}+$ $199,46 \mathrm{gr}$

$=1063.41 \mathrm{gr}$

c. Variasi III 30\% (Semen 20\%:Pasir 50\%: Serbuk Gergaji Kayu 30\%) dengan faktor air semen 0,35 yaitu:

Untuk berat semen yang dibutuhkan untuk 1 wadah dimana $20 \%$ dari volume wadah $=20 \% \times 569,91 \mathrm{~cm}^{3}$

$$
=113,982 \mathrm{~cm}^{3}
$$

Jadi berat yang dibutuhkan $=113,982 \mathrm{~cm}^{3} \mathrm{x}$ berat jenis semen $=113,982 \mathrm{~cm}^{3} \times 3,1 \mathrm{gr} / \mathrm{cm}^{3}$

$=353,34 \mathrm{gr}$

Untuk pasir yang dibutuhkan untuk 1 wadah dimana $50 \%$ dari volume wadah

$$
\begin{aligned}
& =50 \% \times 569,91 \mathrm{~cm}^{3} \\
& =284,95 \mathrm{~cm}^{3}
\end{aligned}
$$

Jadi berat yang dibutuhkan

$$
\begin{aligned}
& =284,95 \mathrm{~cm}^{3} \times \text { Berat jenis pasir } \\
= & 284,95 \mathrm{~cm}^{3} \times 1,4 \mathrm{gr} / \mathrm{cm}^{3} \\
= & 398,93 \mathrm{gr}
\end{aligned}
$$

Untuk berat serbuk gergaji kayu yang dibutuhkan untuk 1 wadah dimana 30\% dari volume wadah $=30 \% \times 569,91 \mathrm{~cm}^{3}$

$$
=170,973 \mathrm{~cm}^{3}
$$

Jadi berat yang dibutuhkan

$=170,973 \mathrm{~cm}^{3} \mathrm{x}$ berat jenis serbuk kayu

$$
\begin{aligned}
& =170,973 \mathrm{~cm}^{3} \times 0,28 \mathrm{gr} / \mathrm{cm}^{3} \\
& =47,87 \mathrm{gr}
\end{aligned}
$$

Untuk faktor air semen yang dibutuhkan adalah $35 \%$ dimana 35\% dari volume wadah

$$
\begin{aligned}
= & 35 \% \times 569,91 \mathrm{~cm}^{3} \\
= & 199,46 \mathrm{~cm}^{3}
\end{aligned}
$$

Jadi berat yang dibutuhkan

$=199,46 \mathrm{~cm}^{3} \mathrm{x}$ berat jenis air

$=199,46 \mathrm{~cm}^{3} \times 1 \mathrm{gr} / \mathrm{cm}^{3}$

$=199,46 \mathrm{gr}$

Jadi jumlah total berat campuran untuk variasi $30 \%$ (semen + pasir +Serbuk gergaji kayu) 
R. Exaudi Simon Purba, Irwan \& Nurmaidah, Pemanfaatan Limbah Serbuk Gergaji Kayu Sebagai Subtitusi

$$
=353,34 \mathrm{gr}+398,93 \mathrm{gr}+47,87 \mathrm{gr}+
$$

199,46 gr

$$
=997.6 \mathrm{gr}
$$

Hasil dari perhitungan tersebut dapat di lihat pada Tabel 1 berikut :

Tabel 1. Variasi Campuran Material pada Uji Percobaan Kedap Suara

\begin{tabular}{llllll}
\hline $\begin{array}{l}\text { Variasi } \\
\text { Campura } \\
\mathrm{n}\end{array}$ & $\begin{array}{l}\text { Seme } \\
\mathrm{n} \\
(\mathrm{gr})\end{array}$ & $\begin{array}{l}\text { Pasir } \\
(\mathrm{gr})\end{array}$ & $\begin{array}{l}\text { Serbu } \\
\text { k kayu } \\
(\mathrm{gr})\end{array}$ & $\begin{array}{l}\text { Air } \\
(\mathrm{gr})\end{array}$ & $\begin{array}{l}\text { Total } \\
(\mathrm{gr})\end{array}$ \\
\hline $\begin{array}{l}\text { Campura } \\
\text { n o \% }\end{array}$ & 353,3 & $\begin{array}{l}638, \\
2\end{array}$ & o & $\begin{array}{l}199, \\
4\end{array}$ & 1191,0 \\
\hline $\begin{array}{l}\text { Campura } \\
\text { n 20\% }\end{array}$ & \multirow{2}{3}{353,3} & $\begin{array}{l}478, \\
7\end{array}$ & 31,9 & $\begin{array}{l}199, \\
4\end{array}$ & $\begin{array}{l}1063, \\
4\end{array}$ \\
\hline $\begin{array}{l}\text { Campura } \\
\text { n 30\% }\end{array}$ & \multirow{2}{3}{353,3} & $\begin{array}{l}398, \\
9\end{array}$ & 47,87 & $\begin{array}{l}199, \\
4\end{array}$ & 997,6 \\
\hline
\end{tabular}

Sumber : Penelitian, 2017

Jumlah air untuk campuran beton pada umumnya dihitung berdasarkan nilai perbandingan antara berat air dan berat semen portland pada campuran adukan, dan pada Peraturan Beton Indonesia (PBI 1971) dikenal dengan istilah faktor air semen yang disingkat fas, sedangkan peraturan pengganti SNI 03-2847-2002) disebut rasio air semen yang disingkat ras atau water coment ratio (wcr), dalam buku Ali Asroni 2010. Balok dan pelat beton bertulang mencari fas dirumuskan sebagai berikut :

Fas atau ras $=$

$\frac{\text { Berat air pada campuran beton }}{\text { Beratsemen pada campuran beton }}$

Jadi faktor air semen yang digunakan dalam penelitian ini adalah:

Fas atau ras $=\frac{\underset{199,46}{353,34}}{}=0,56$
Dalam menentukan campuran beton dalam hal ini ditentukan dengan metode pencampuran dengan metode perbandingan volume wadah dengan volume semen, volume pasir, volume serbuk gergaji kayu dan faktor air semen. Sebelum melakukan pencetakan terlebih dahulu dicari massa jenis dari setiap benda yang dicampur yaitu berat jenis pasir = $1400 \mathrm{~kg} / \mathrm{m}^{3}$, berat jenis semen $=3100$ $\mathrm{kg} / \mathrm{m}^{3}$, berat jenis air $=1000 \mathrm{~kg} / \mathrm{m}^{3}$ dan berat jenis serbuk gergaji kayu adalah 0,28 $\mathrm{gr} / \mathrm{cm}^{3}$.

Dalam menentukan proporsi campuran dalam penelitian ini berdasarkan pada SK SNI 03-2834-2000 Tata Cara pembuatan Rencana Campuran Beton Normal dan diperoleh komposisi campuran dalam perbandingan berat, yang didasarkan oleh perhitungan volume benda uji yaitu :

$$
\begin{aligned}
& V=\pi r^{2} t \\
& V=3,14 \cdot 5,5^{2} \cdot 6 \\
& V=569,91 \mathrm{~cm}^{3}
\end{aligned}
$$

Variasi persentase serbuk gergaji kayu yang digunakan adalah 0\%, 20\% dan $30 \%$. Untuk mengetahui nilai serap bising beton maka dibuat benda uji berbentuk silinder dengan diameter $11 \mathrm{~cm}$ dan tinggi $6 \mathrm{~cm}$ masing-masing sebanyak 6 buah untuk benda uji beton normal dan untuk beton dengan penambahan serbuk gergaji kayu. Setelah umur beton 24 jam, cetakan 
silinder dibuka dan mulai dilakukan perendaman selama 28 hari dan didasarkan pada SNI 1972:2008.

\section{HASIL DAN PEMBAHASAN}

Hasil dari perhitungan timbangan berat benda uji sebelum peredaman dapat dilihat pada Tabel 2. Setelah melakukan perendaman sekitar 7 hari untuk proses pengikatan semen yang lebih baik terutama dengan serbuk gergaji kayu, proses perendaman didasarkan pada PBI 1971, maka ditimbang kembali untuk mengetahui besarnya daya absorbsi beton dan hasil dari perhitungan timbangan berat benda uji sesudah peredaman dapat dilihat pada Tabel 3.

Tabel 2. Hasil Timbangan Berat Benda Uji Sebelum Peredaman

\begin{tabular}{lllllll}
\hline \multirow{2}{*}{ Campuran } & \multicolumn{6}{l}{ Sampel (gr) } \\
\cline { 2 - 7 } & I & II & III & IV & V & VI \\
\hline 0\% & 1302 & 1316 & 1264 & 1301 & 1304 & 1252 \\
\hline $20 \%$ & 1088 & 1119 & 1128 & 1094 & 1088 & 1104 \\
\hline $30 \%$ & 1030 & 1101 & 1052 & 1035 & 1015 & 1062 \\
\hline
\end{tabular}

Sumber : Penelitian, 2017

Tabel 3. Hasil Timbangan Berat Benda Uji Sesudah Peredaman

\begin{tabular}{lllllll}
\hline Camp & \multicolumn{6}{l}{ Sampel (gr) } \\
\cline { 2 - 6 } uran & I & II & III & IV & V & VI \\
\hline o\% & 1338 & 1343 & 1289 & 1328 & 1328 & 1280 \\
\hline $20 \%$ & 1119 & 1140 & 1154 & 1114 & 1111 & 1128 \\
\hline $30 \%$ & 108 & 1138 & 1062 & 108 & 105 & 106 \\
& 8 & & & 5 & 4 & 6 \\
\hline
\end{tabular}

Sumber : Penelitian, 2017

Dengan mengurangkan berat benda

uji sebelumnya dengan berat benda uji setelah perendaman dibagi dengan berat benda uji sebelumnya dan di kali dengan persen maka akan didapatkan berat absorbsi yang terjadi adalah pada Tabel 4 . Dari tabel tersebut dapat dilihat bahwa absorsi yang paling besar adalah pada $30 \%$ yaitu pada sampel I.

Tabel 4. Absorbsi Masing-Masing Benda Uji

\begin{tabular}{lllllll} 
Camp & \multicolumn{6}{l}{ Sample (\%) } \\
\cline { 2 - 7 } uran & I & II & III & IV & V & VI \\
\hline o\% & 0,36 & 0,27 & 0,25 & 0,27 & 0,24 & 0,28 \\
\hline $20 \%$ & 0.31 & 0,21 & 0,26 & 0,20 & 0,23 & 0,24 \\
\hline $30 \%$ & 0.58 & 0,37 & 0,10 & 0.50 & 0.39 & 0.04 \\
\hline
\end{tabular}

Sumber : Penelitian, 2017

Tabel 5. Pengujian Kedap Suara pada Campuran Beton dengan Serbuk Gergaji Kayu o\%

\begin{tabular}{llllll} 
Sam & \multicolumn{5}{l}{ Frekuensi (Hz) } \\
\cline { 2 - 6 } pel & 250 & 500 & 1000 & 2000 & 4000 \\
\hline I & 0.243 & 0.067 & 0.184 & 0.235 & 0.210 \\
\hline II & 0.478 & 0.016 & 0.052 & 0.058 & 0.223 \\
\hline III & 0.451 & 0.009 & 0.037 & 0.400 & 0.388 \\
\hline IV & 0.301 & 0.025 & 0.383 & 0.335 & 0.357 \\
\hline V & 0.480 & 0.025 & 0.330 & 0.089 & 0.318 \\
\hline VI & 0.487 & 0.067 & 0.184 & 0.232 & 0.124 \\
\hline
\end{tabular}

Sumber : Penelitian, 2017

Grafik 1. Frekuensi terhadap koefisien serap bunyi pada variasi $0 \%$

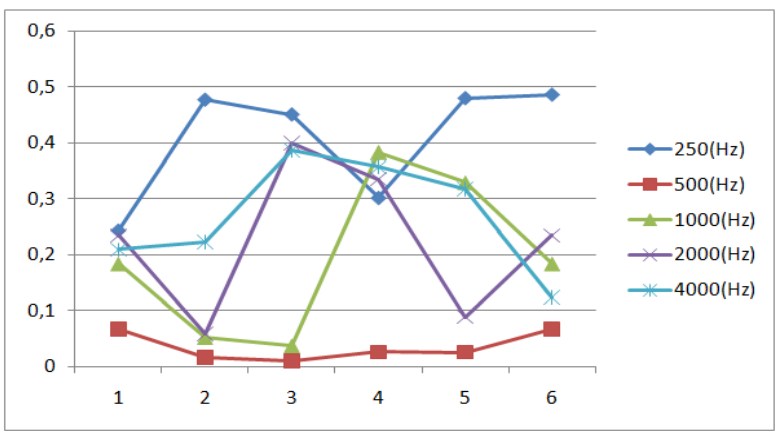

(Sumber : Penelitian, 2017)

Dari grafik 1 diatas menunjukkan bahwa pada komposisi 0\% menunjukkan nilai absorbsi terbesar adalah ditunjukkan oleh frekuensi $250 \mathrm{~Hz}$ sampel VI. 
R. Exaudi Simon Purba, Irwan \& Nurmaidah, Pemanfaatan Limbah Serbuk Gergaji Kayu Sebagai Subtitusi

Tabel 6. Pengujian Kedap Suara pada Campuran Beton dengan Serbuk Gergaji Kayu $20 \%$

\begin{tabular}{cccccc}
\hline Sam & \multicolumn{5}{c}{ Frekuensi (Hz) } \\
\cline { 2 - 6 } pel & 250 & 500 & 1000 & 2000 & 4000 \\
\hline I & 0.322 & 0.367 & 0.284 & 0.445 & 0.390 \\
\hline II & 0.378 & 0.216 & 0.352 & 0.368 & 0.323 \\
\hline III & 0.461 & 0.209 & 0.337 & 0.360 & 0.418 \\
\hline IV & 0.501 & 0.225 & 0.283 & 0.375 & 0.357 \\
\hline V & 0.480 & 0.225 & 0.340 & 0.289 & 0.388 \\
\hline VI & 0.387 & 0.267 & 0.384 & 0.437 & 0.194 \\
\hline
\end{tabular}

Sumber : Penelitian, 2017

Grafik 2. Frekuensi terhadap koefisien serap bunyi pada variasi $20 \%$

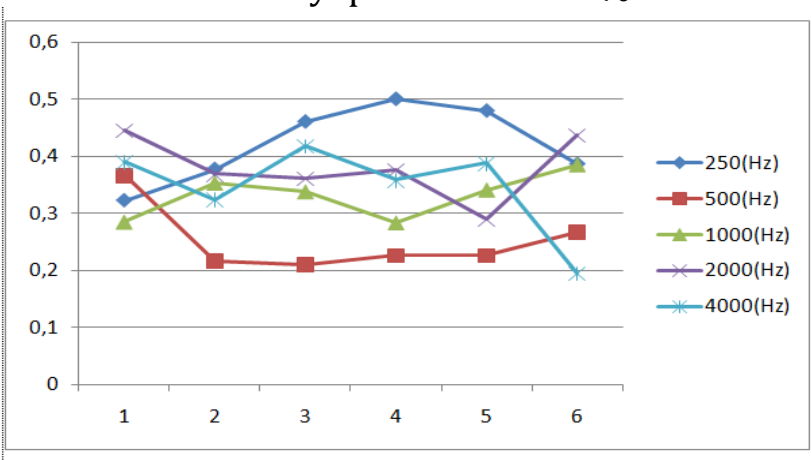

Sumber : Penelitian, 2017

Dari Grafik 2 di atas menunjukkan bahwa pada komposisi 20\% menunjukkan nilai absorbsi terbesar adalah ditunjukkan oleh frekuensi $250 \mathrm{~Hz}$ sampel IV.

Tabel 7. Pengujian Kedap Suara pada Campuran Beton dengan Serbuk Gergaji Kayu 30\%

Sampel Frekuensi(Hz)

\begin{tabular}{llllll}
\cline { 2 - 6 } & 250 & 500 & 1000 & 2000 & 4000 \\
\hline I & 0.631 & 0.677 & 0.615 & 0.505 & 0.358 \\
\hline II & 0.578 & 0.516 & 0.552 & 0.668 & 0.623 \\
\hline III & 0.661 & 0.609 & 0.437 & 0.460 & 0.418 \\
\hline IV & 0.561 & 0.425 & 0.683 & 0.575 & 0.557 \\
\hline VI & 0.490 & 0.525 & 0.640 & 0.589 & 0.588 \\
\hline
\end{tabular}

Sumber : Penelitian, 2017
Grafik 3. Frekuensi Terhadap Koefisien Serap Bunyi pada Variasi 30\%

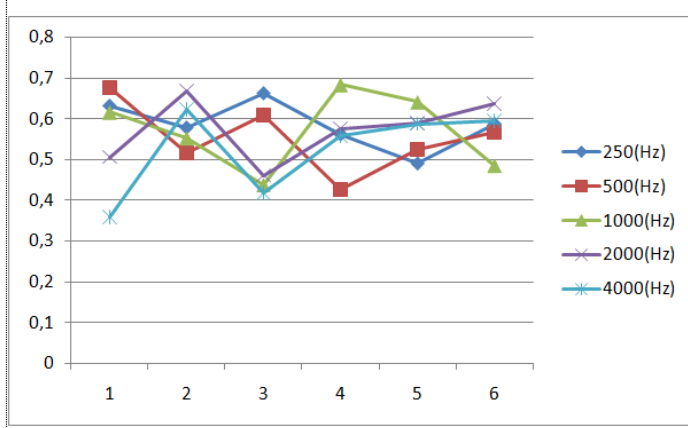

Sumber : Penelitian, 2017

Dari grafik 3 di atas menunjukkan bahwa pada komposisi 30\% menunjukkan nilai absorbsi terbesar adalah ditunjukkan oleh frekuensi $1000 \mathrm{~Hz}$ sampel IV.

Sehingga dari keseluruhan grafik menunjukkan bahwa pada campuran 30\% serbuk gergaji kayu yaitu pada variasi keIII menunjukkan nilai koefisien serap bunyi terbesar yaitu 0.6832 pada sampel 4 dengan frekuensi $1000 \mathrm{~Hz}$ dengan koefisien absorbsi $0,50 \%$ dan dengan kecepatan rambat gelombang bunyi menunjukkan $683,2 \mathrm{~m} /$ det dengan metode serbuk gergaji kayu sebagai subtitusi agregat. Berdasarkan penelitian sebelumnya yang dilakukan oleh Muslimin Lubis dengan pencampuran atau pengadukan secara merata pada material sampel, nilai koefisien serap bunyi tertinggi adalah 0,316 pada frekuensi 250 $\mathrm{Hz}$ dengan variasi 5\%. Dari hasil penelitian ini dapat disimpulkan bahwa semakin banyak penggunaan serbuk gergaji kayu 
pada benda uji maka kemampuan serap suaranya akan semakin baik sedangkan pada benda uji yang semakin sedikit dan tidak menambahkan serbuk gergaji kayu sebagai subtitusi agregat halus maka penyerepan suara akan kurang baik hal ini disebabkan karena sisi luar benda uji terlalu rapat sedangkan kemampuan serap suara akan lebih baik jika permukaan memiliki rongga.

\section{SIMPULAN}

Nilai koeefisien serap bunyi menunjukkan grafik yang semakin meningkat pada setiap penambahan variasi serbuk gergaji kayu. Nilai koefisien serap bunyi terendah adalah 0.0094 pada frekuensi $500 \mathrm{~Hz}$ variasi $0 \%$, sedangkan nilai koefisien serap bunyi tertinggi adalah 0.6832 pada frekuensi $1000 \mathrm{~Hz}$ variasi $30 \%$. Nilai cepat rambat gelombang bunyi terendah $4,7 \mathrm{~m} / \mathrm{s}$ pada frekuensi $500 \mathrm{~Hz}$ variasi $0 \%$, sedangkan cepat rambat gelombang bunyi terbesar 2495,2 m/s pada frekuensi $4000 \mathrm{~Hz}$ variasi $30 \%$. Dari penelitian ini, disimpulkan bahwa penambahan serbuk gergaji kayu dapat mempengaruhi/bertambahnya nilai serap semakin baik.

\section{DAFTAR PUSTAKA}

Angus J. Macdonald. (2001). Struktur \& Arsitektur. Jakarta: Erlangga

Anonim, (1990). Tata Cara Pembuatan Rencana Campuran Beton Normal (SK SNI T 151990-03), Departemen Pekerjaan Umum

Christina E. Mediastika, Ph.D. (2005). Akustika Bangunan. Jakarta: Erlangga

Dangzt, iman. 2014(http://civilkitau.blogspot.com/2014 /03/komposisi semen portland dan fungsinya.html) 20 Mei 201516.53.

DEPARTEMEN PU. (1989), SNI 03-0349-1989, Bata beton untuk pasangan dinding, Balitbang, Jakarta

Sunggono kh, (1984),Teknik Sipil. Bandung: Nova Wiratman Wangsadinata, Dkk Panitia pembaruan PBI. (1971). peraturan beton bertulang Indonesia. Bandung: Direktorat penyelidikan masalah bangunan.

Leslie L Doelle, Lea Prasetio, (1985), Akustik Lingkungan, Jakarta, Erlangga, hal. 15-22

Prasasto Satwiko, (2004), Fisika Bangunan 2.Andi Jogjakarta, hal 14-162 